\title{
INTERPRETIVE SUMMARIES, MAY 2010
}

Influence of microfiltration and adjunct culture on quality of Domiati cheese. By Awad et al., page 180\%. Pasteurization of milk has a negative effect on the natural flora present in raw milk and modifies some physicochemical properties of milk. Microfiltration constitutes an alternative to heat treatment to reduce the presence of bacteria and improve the microbiological safety of dairy products without modifying the physicochemical properties of milk. Fourteen treatments of Domiati cheese were made from pasteurized or microfiltered milk with added selected adjunct culture to improve the quality of cheese. The chemical composition of cheeses seems to be affected by milk treatment (microfiltration or pasteurization) rather than the culture types. Cheeses made from microfiltered milk received higher scores for body and texture compared with cheeses made from pasteurized milk.

Improved growth of bifidobacteria by cocultivation with Lactococcus lactis subspecies lactis. By Yonezawa et al., page 1815. Growth of bifidobacteria in skim milk medium was found to be stimulated upon cocultivation with certain strains of Lactococcus lactis. Bifidobacterium growth stimulating (BGS) activity was associated with the presence of a cell wall-anchored proteinase (PrtP) in Lactococcus lactis. Casein hydrolysates by cells of Lactococcus lactis exhibited BGS activity. A combination of two amino acids, methionine and leucine, was found to account for a large portion of the casein hydrolysate BGS activity. This cocultivation system is industrially applicable for the production of fermented milk with high cell counts of bifidobacteria.

Direct application of supercritical carbon dioxide for the reduction of Cronobacter spp. (Enterobacter sakazakii) in end-products of dehydrated powdered infant formula. By Kim et al., page 1854. Cronobacter spp. have been isolated from end products of dehydrated powered infant formula (PIF) that had been subjected to thermal treatment during production. The supercritical carbon dioxide $\left(\mathrm{SC}-\mathrm{CO}_{2}\right)$ treatment that continues to attract attention as a nonthermal technique was used for inactivation of Cronobacter spp. in dehydrated PIF. Treatment with $\mathrm{SC}-\mathrm{CO}_{2}$ under certain conditions completely inactivated the colony forming capabilities of Cronobacter spp. $\left(6.32 \log _{10} \mathrm{cfu} / \mathrm{g}\right)$. The $\mathrm{SC}-\mathrm{CO}_{2}$ did not affect the water activity, $\mathrm{pH}$, and color of PIF. Our results indicate that $\mathrm{SC}-\mathrm{CO}_{2}$ are feasibly applicable to the end-product of dehydrated PIF and can effectively kill Cronobacter spp. in PIF without altering the physical properties of the product.

Modification of the analysis of parathyroid hormone-related protein in milk and concentra- tions of this protein in commercial milk and milk products in Japan. By Onda et al., page 1861. Parathyroid hormone-related protein (PTHrP) can cause hypercalcemia associated with malignant tumors. However, the physiological roles of this protein when present in high concentrations in milk remain unclear. This experiment shows that the combination of the pretreatment and diluent used to process milk greatly influences the PTHrP concentration in milk and that a certain amount of bovine PTHrP is ingested by humans through commercial milk and milk products.

Chemical and biochemical study of industrially produced San Simón da Costa smoked semihard cow's milk cheeses: Effects of storage under vacuum and different modified atmospheres. $B y$ Garabal et al., page 1868. Chemical, biochemical, and sensorial parameters that may be affected by storage in modified-atmosphere packaging of a smoked, semihard cow's milk cheese (San Simón da Costa) were investigated. Modified atmospheres altered the ripening process and led to accumulation of several smokederived compounds, which were negatively correlated with flavor. Nevertheless, vacuum packaging appeared to be the most useful technique in terms of preserving the sensory quality. International market expansion has led to demands for packaged samples of the product at distribution and selling points, and the results obtained in this study will be of great interest to the cheese industry.

Comparison between red-green-blue imaging and visible-near infrared reflectance as potential process analytical tools for monitoring syneresis. By Mateo et al., page 1882. The present study compared 2 on-line optical sensing systems, namely red-greenblue imaging and visible-near infrared reflectance, to monitor the volume of whey produced during syneresis in a cheese vat. Models were generated over a range of temperature treatments and their prediction accuracy was compared in order to select a process analytical tool for monitoring syneresis in the cheese industry. The 2 systems predicted syneresis without significant difference between them. However, a single-wavelength near infrared model was the most parsimonious.

Roles of charge interactions on astringency of whey proteins at low pH. By Vardhanabhuti et al., page 1890. Whey proteins are a major ingredient in sports drinks and functional beverages. At low $\mathrm{pH}$, whey proteins are astringent, which can be undesirable in certain applications. Results from this study show that astringency of whey proteins at low $\mathrm{pH}$ is attributable to the proteins themselves and not just the acid alone. Charge interactions between whey proteins and 
saliva appear to play a role in astringency. These findings suggest that decreasing the interactions between whey and saliva proteins will minimize the astringency of whey protein beverages.

Role of protein concentration and protein-saliva interactions in the astringency of whey proteins at low pH. By Kelly et al., page 1900. This study investigated the effect of protein concentration on astringency of whey protein beverages at low $\mathrm{pH}$. Increasing protein concentration from 0.25 to $4 \%$ increased astringency of beverages and astringency plateaued at higher protein concentrations. When compared with control beverages made with phosphate buffers, whey protein beverages were more astringent, indicating that proteins contributed to astringency. Interactions between saliva and whey proteins were shown by in vitro turbidity measurement. Both in vitro and sensory studies revealed that astringency of whey proteins was dependent on the combined effects of $\mathrm{pH}$ and protein concentrations.

Survey of the fatty acid composition of retail milk differing in label claims based on production management practices. By O'Donnell et al., page 1918. Consumers are increasingly health conscious and the dairy case often includes specialty labeled milk based on production management practices such as recombinant bovine somatotropin-free or organic in addition to conventional milk. This labeling may be misunderstood and perceived by consumers to reflect differences in milk quality. We compared the fatty acid composition of conventional milk with milk labeled as recombinant bovine somatotropin-free or organic. Analyses included saturated and unsaturated fatty acids and bioactive fatty acids that may influence health. We found no differences among milk label types that would be of importance from a public health perspective.

Identification of the bacterial biodiversity in koumiss by denaturing gradient gel electrophoresis and species-specific polymerase chain reaction. By Hao et al., page 1926. Bacterial biodiversity in traditional koumiss fermented milk was studied by denaturing gradient gel electrophoresis and speciesspecific polymerase chain reaction. The results revealed a novel bacterial profile and extensive bacterial biodiversity in koumiss. The dominant lactic acid bacteria identified were Lactobacillus acidophilus, Lactobacillus helveticus, Lactobacillus fermentum, and Lactobacillus kefiranofaciens. This is the first systematic study of microbial composition in koumiss, and these findings will be helpful in selecting appropriate strains for the manufacture of this product at the industrial level.

In vitro and in vivo analysis of fatty acid effects on metabolism of $17 \beta$-estradiol and progesterone in dairy cows. By Piccinato et al., page 1934. Dietary fat supplementation has been used in the dairy industry to improve productivity and reproductive performance. The present study evaluated the effect of fatty acids on inhibition of steroid hormone metabolism. In cultures of bovine liver slices, high concentrations of fatty acids $(100-300 \mu M)$, particularly the polyunsaturated fatty acid linolenic acid (C18:3), inhibited metabolism of progesterone and estradiol. However, there was no detectable effect on progesterone and estradiol metabolism by in vivo supplementation of cows with linseed oil (rich in C18:3). Thus, polyunsaturated fatty acids have the potential to inhibit steroid hormone metabolism, but it may be difficult to supplement sufficient fatty acids to produce this effect in vivo.

Effects of treatment of anestrous dairy cows with gonadotropin-releasing hormone, prostaglandin, and progesterone. By McDougall, page 1944. Dairy cows that had not been detected in estrus by $9 \mathrm{~d}$ before the start of a breeding program were randomly assigned to 1 of 4 treatments. A treatment that included progesterone, gonadotropin-releasing hormone, and prostaglandin $\mathrm{F}_{2 \alpha}$ resulted in earlier conception compared with a combination of gonadotropin-releasing hormone and prostaglandin $\mathrm{F}_{2 \alpha}$ or no treatment.

Efficacy of enrofloxacin in the treatment of naturally occurring acute clinical Escherichia coli mastitis. By Suojala et al., page 1960. Treatment of acute clinical Escherichia coli mastitis with enrofloxacin was studied under field conditions. Enrofloxacin treatment did not improve the clinical or bacteriological cure assessed $21 \mathrm{~d}$ after treatment. Enrofloxacin treatment significantly improved bacteriological cure on $\mathrm{d} 2$ post-treatment, but decreased clinical cure on d 2. Our study did not support the use of enrofloxacin to treat acute E. coli mastitis.

Sampling strategies for monitoring lameness in dairy cattle. By Main et al., page 1970. Observing all cattle as they leave the milking parlor is a common but time-consuming method for assessing lameness within a herd of dairy cattle. This study examines the potential for sampling a proportion of these cattle and concludes that observing up to 100 cows from the middle of the milking order may yield a reasonable estimate of true prevalence. It suggests that identifying farms that have severely lame cattle present at the end of milking may highlight those farms that are more likely to benefit from further support.

Relationship between feeding strategy, lying behavior patterns, and incidence of intramammary infection in dairy cows. By DeVries et al., page $198 \%$. A study was conducted to investigate whether feeding strategy influences post-milking standing times in tie 
stall-housed dairy cows and to determine whether this time relates to incidence of intramammary infection. The results suggest that post-milking standing times can be increased by providing fresh feed close to the time of milking. However, the results also show that the use of such a feeding strategy is not effective in the prevention of intramammary infection in tie stallhoused cows.

Limits to prediction of energy balance from milk composition measures at individual cow level. By Løvendahl et al., page 1998. Monitoring cows' energy balance is important for management of dairy cow feeding and for obtaining good reproduction results. Estimation of energy balance from frequent measures of milk composition be available with in-line milk analysis at milking. Although estimates of energy balance based on milk is accurate for averages of groups of cows, they have limited accuracy at the level of individuals, especially compared with similar traits based on live weight and body condition scores.

Automated methods for detecting lameness and analgesia in dairy cattle. By Chapinal et al., page 200\%. Automated measures of time spent lying down and how cows distribute their weight between their legs can detect lame cows. Lame cows shift weight between contralateral legs more often, lie down for more time, and walk slower than nonlame cows. Injections of ketoprofen decreased the shifting of weight between legs but did not affect other behavioral signs of lameness.

Heifers infected with coagulase-negative staphylococci in early lactation have fewer cases of clinical mastitis and higher milk production in their first lactation than noninfected heifers. By Piepers et al., page 2014. Intramammary infections in recently calved heifers are more common than was formerly believed. Still, the relevance of these infections for the heifers' future performances has been studied only sparsely. In the present study, the association between the infection status of fresh heifers and their udder health, milk production, and culling hazard during first lactation was explored. We concluded that although coagulase-negative staphylococci cause the majority of intramammary infections around calving, they should not be cause for serious concern because they seem harmless for future milk production.

Vitamin $D_{3}$ synthesis in the entire skin surface of dairy cows despite hair coverage. By Hymøller and Jensen, page 2025. It is presently unknown how cows, as hair covered animals, can produce vitamin $\mathrm{D}_{3}$ endogenously during exposure to summer sunlight when humans covered in clothing are unable to synthesise the vitamin. Different scenarios have been suggested (e.g., that vitamin $\mathrm{D}_{3}$ is synthesised from sebum on the hair and ingested by cows during grooming, or that body areas scarcely covered in hair, like udder and muzzle, exclusively produce the vitamin) but never have put to the test in cows. The present study on cows, which had their bodies covered with horse blankets and udder covers to varying degrees during summer in Denmark, showed that cows do produce vitamin $\mathrm{D}_{3}$ all over their body surface despite their hair coverage.

Short communication: Effect of sampling time relative to the first daily feeding on interpretation of serum fatty acid and $\beta$-hydroxybutyrate concentrations in dairy cattle. By Quiroz-Rocha et al., page 2030. Measurement of the concentrations of nonesterified fatty acids (NEFA) and $\beta$-hydroxybutyrate (BHBA, a ketone body) in blood serum provide insight into aspects of energy metabolism in dairy cows in the peripartum period. This study reinforces that whereas BHBA does not vary importantly around delivery of fresh feed, NEFA concentrations are considerably higher $1 \mathrm{~h}$ before feeding than at 4 or $10 \mathrm{~h}$ after feeding, and that there is twice the probability determining NEFA values $\geq 0.04 \mathrm{mmol} / \mathrm{L}$ at the former time.

Interactions of energy and predicted metabolizable protein in determining nitrogen efficiency in the lactating dairy cow. By Rius et al., page 2034. Mid-lactation dairy cows were fed ad libitum diets with recommended or less than recommended concentrations of metabolizable protein (MP) and energy. The effects of MP and dietary energy on milk yield were independent, with cows responding to dietary energy even when they were protein deficient. Nitrogen efficiency was maximized with high dietary energy and low MP. The National Research Council model (2001) underpredicted production when MP was reduced in cows fed the high energy diet because of the assumption of fixed conversion efficiency for postabsorptive N.

Effects of feeding triticale dried distillers grains plus solubles as a nitrogen source on productivity of lactating dairy cows. By Oba et al., page 2044. Dried distillers grains plus solubles (DDGS) is a coproduct of ethanol production. Cows fed corn DDGS decreased milk protein yield compared with those fed canola meal or soybean meal. However, cows fed triticale DDGS had similar milk protein yield as those fed canola meal or soybean meal. Triticale DDGS can replace canola meal or soybean meal in the diets of lactating dairy cows without adverse effects on production.

Effects of hunger level and tube diameter on the feeding behavior of teat-fed dairy calves. By Herskin et al., page 2053. We examined the relation between sucking behavior and 3 different hunger levels of dairy calves fed by teat buckets. Drinking rate was 
reduced at a tube diameter of $1.5 \mathrm{~mm}$. Hunger level did not change drinking rate but did affect the performance of nonnutritive sucking and butting: calves performed more nonnutritive sucking and butting towards the teat when hungrier, and less when hunger was reduced. The results suggest that nonnutritive sucking is a more sensitive indicator than drinking rate of changes in feeding motivation.

Transfer efficiency of melamine from feed to milk in lactating dairy cows fed with different doses of melamine. By Shen et al., page 2060. When dairy cows consume melamine-tainted feed, melamine may be transferred into the milk, which places human health at risk. This study evaluated the transfer efficiency of melamine from feed containing different doses of melamine to milk. When fed at a dose lower than 450 $\mathrm{mg} / \mathrm{cow}$ per day, the transfer efficiency of melamine from feed to milk was not affected by melamine doses but was correlated with milk yield. The milk melamine concentration was linearly related with melamine intake levels. The present study indicated that when the daily intake of melamine exceeds $312.7 \mathrm{mg} / \mathrm{cow}$, the milk should not be used to produce infant formula powder.

Anionic salts in the prepartum diet and addition of sodium bicarbonate to colostrum replacer, and their effects on immunoglobulin G absorption in the neonate. By Morrill et al., page $206 \%$. Calves are born without in utero transfer of maternal immunity and must receive protective antibodies from colostrum. Calves born from cows fed diets containing anionic salts to prevent postpartum metabolic disorders may have diminished absorption of colostral antibodies because of respiratory acidosis. Adding sodium bicarbonate to colostrum may help correct this problem. Results indicated that feeding cows diets that contain anionic salts did not affect serum immunoglobulin G concentrations in resulting calves. However, adding sodium bicarbonate to a dried colostrum replacement product increased serum immunoglobulin G concentration in calves regardless of their dam's diet.

Effects of partial replacement of concentrate with feed blocks on nutrient utilization, microbial $\mathbf{N}$ flow, and milk yield and composition in goats. By Molina-Alcaide et al., page 2076. Goats provide important food resources in both developed and developing countries. Feed blocks, a solidified mixture of unconventional feeds like agroindustrial byproducts, urea, binder, and minerals are cost-effective alternative feed supplements that could improve farmers' income and contribute to environment protection. This study investigates the effect of feed blocks on ruminal fermentation and milk yield and composition. Feed blocks promoted less milk production, but health quality was improved.
Effect of diet on fecal and urinary estrogenic activity. By Tucker et al., page 2088. Accumulation of estrogenic compounds in the environment is of growing concern because of their ability to disrupt the endocrine system of sensitive species, and dietary phytoestrogens may contribute to estrogenic activity of livestock manure. We evaluated the effect of red clover hay-based diet (high in phytoestrogens) on estrogenic activity of manure of dairy heifers. Feeding red clover increased fecal and urinary estrogenic activity measured with a bioassay. Seven distinct phytoestrogens were detected in feces with liquid chromatography-tandem mass spectrometry, and excretion of 5 of these was greater in heifers fed red clover. Identifying sources of variation in estrogenic activity in livestock manure will aid in development of practices to reduce environmental estrogen accumulation.

Response of lactating dairy cows to high-protein distillers grains or 3 other protein supplements. By Christen et al., page 2095. High-protein distillers grains (HPDDG) is a high-protein, lower fat product of ethanol processing that is available to the feed industry. When fed to lactating cows as the source of supplemental protein, HPDDG was equal to soybean meal, canola meal, and traditional distillers grains with solubles in supporting milk protein production. Cows fed the HPDDG diet produced the most casein in milk protein and thus it may have provided the most desirable amino acid profile for casein production.

Effect of rumen-protected methionine on feed intake, milk production, true milk protein concentration, and true milk protein yield, and the factors that influence these effects: A metaanalysis. By Patton, page 2105. Farmers and nutritionists question the response to feeding rumen-protected methionine (RPM). This summary of published studies found that RPM feeding increased true milk protein percentage (approximately 0.07\%) and yield while slightly increasing milk yield. This study suggests that production response is affected by forages fed, cattle breed, and RPM product used, but is not affected by methionine or lysine status.

Carryover effects of potassium supplementation on calcium homeostasis in dairy cows at parturition. By Bhanugopan et al., page 2119. Pasture rich in potassium can lead to cows collapsing at calving because of a condition called milk fever. The period of greatest risk is thought to be the few days around calving. In this study we tested the importance of bone as a supplier of nutrients to reduce the risk of milk fever. Bone appeared to have no effect, but the data indicated that the period of risk is longer than a few days. It may instead extend to at least $11 \mathrm{~d}$ before calving, meaning that nutritional strategies to prevent milk fever should 
be implemented much earlier than commonly recommended.

Effects of supplementary folic acid and vitamin $\mathrm{B}_{12}$ on hepatic metabolism of dairy cows according to methionine supply. By Preynat et al., page 2130. Methionine supplements, as donor of preformed methyl groups, affected the expression of genes related to the methylation cycle. Supplementary folic acid and vitamin $\mathrm{B}_{12}$ given together increased gene expression of the vitamin $\mathrm{B}_{12}$-dependent enzyme, methylmalonylCoA mutase, essential for propionate utilization in gluconeogenesis. The combined supplement of folic acid and vitamin $\mathrm{B}_{12}$ probably improved efficiency of energy metabolism in liver of dairy cows during early lactation.

Brown midrib corn silage and Tifton 85 bermudagrass in rations for early lactation cows. By Castro et al., page 2143. Forages with higher fiber digestibility allow greater forage utilization and reduce the amount of supplemental energy required to meet requirements for lactation. The potential of incorporating brown midrib corn silage and Tifton 85 (T85) bermudgrass hay into rations for early lactating cows was examined. Enhanced dry matter and fiber intake was achieved by cows fed brown midrib corn silage. Including T85 at $10 \%$ of dry matter increased ruminal $\mathrm{pH}$ and acetate concentrations supporting higher milk fat percentage and acceptable energy-corrected milk yield. Use of T85 as a digestible fiber source can sustain acceptable performance levels and promote animal health.

Effects of feeding supplemental organic iron to late gestation and early lactation dairy cows. By Weiss et al., page 2153. Iron is a required nutrient for dairy cows but the effects of feeding supplemental iron have not been evaluated for several decades even though milk yields have increased substantially during that period. Starting $60 \mathrm{~d}$ before anticipated calving through $63 \mathrm{~d}$ after calving, cows were fed diets with 0 or $30 \mathrm{mg} / \mathrm{kg}$ of supplemental iron via an organic supplement. Supplemental iron did not affect measures of iron status, feed intake, or milk production and composition. The iron provided by typical basal diets appears adequate to support milk yields of at least $40 \mathrm{~kg} / \mathrm{d}$.

Hot topic: Gene duplication at the $\alpha$-lactalbumin locus: Finding the evidence in water buffalo (Bubalus bubalus L.). By Rullo et al., page 2161. Studies on milk proteins revealed that a qualitative and quantitative polymorphism may be often found regarding $\alpha$-lactalbumin. In mammals, a similar phenomenon was widely documented in the alpha globin system as the result of a gene duplication. The presence of several, differently expressed $\alpha$-lactalbumin gene (LALBA) products suggests that the mechanism underlying this phenomenon may involve nonallelic genes. To check this hypothesis, an experiment was set up to investigate the LALBA gene arrangement of a water buffalo. Molecular analysis confirms that a tandemly repeated copy of the LALBA gene is present in water buffalo.

Genetic and environmental parameters for milk production, udder health, and fertility traits in Mexican Holstein cows. By Montaldo et al., page 2168. Heritabilities and genetic, environmental, and phenotypic correlations were estimated for 305-d mature equivalent milk, fat, and protein production, somatic cell score (SCS), calving interval, and age at first calving using multiple trait animal models within the first 3 parities in Mexican Holstein cows. No unfavorable genetic relationships between 305-d mature equivalent milk, fat, and protein production, calving interval, and SCS were found. Genetic variation and heritability estimates indicate good prospects for genetic improvement of production traits and possibilities for selection for age at first calving and SCS.

A comparison between Holstein-Friesian and Jersey dairy cows and their $\mathbf{F}_{1}$ hybrid on milk fatty acid composition under grazing conditions. By Palladino et al., page 2176. Conjugated linoleic acid and n-3 polyunsaturated fatty acids are beneficial fatty acids for human health and are present in bovine milk. Previous studies have shown differences between dairy cow breeds but mostly in animals offered total mixed ration diets. The aim of this experiment was to study the effect of cow breed (Jersey vs. Holstein) and their $\mathrm{F}_{1}$ hybrid (Jersey $\times$ Holstein) on milk fatty acid composition under grazing conditions.

Genetic analysis of reproductive disorders and their relationship to fertility and milk yield in Austrian Fleckvieh dual-purpose cows. By Koeck et al., page 2185. This is the first genetic analysis of reproductive disorders for Fleckvieh dual-purpose cows based on data from the Austrian health monitoring project. Heritabilities for threshold models were between 0.01 and 0.14 , whereas heritabilities for linear models were lower, in the range of 0.005 and 0.04 . Although linear models ignore the binary nature of disease traits, genetic evaluation of sires obtained with linear and threshold models were highly correlated. Genetic correlations between reproductive disorders and fertility traits were positive, whereas antagonistic relationships were observed between milk yield in early lactation and reproductive disorders.

Genetic parameters for buffalo milk yield and milk quality traits using Bayesian inference. $B y$ Aspilcueta-Borquis et al., page 2195. Buffalo milk is rich in solid components; this property is highly appreci- 
ated by the milk industry. Few studies have reported genetic parameter estimates for buffalo's milk quality traits. The knowledge of accurate genetic parameters for economically important traits in milking buffaloes is critical to implement a genetic evaluation program. Thus, the objective of the present study was to estimate heritability and correlations for milk, fat, and protein yields, somatic cell score, and fat and protein percentages in buffaloes using Bayesian methodology.

Genetic markers for lactation persistency in primiparous Australian dairy cows. By Pryce et al., page 2202. Associations between single nucleotide polymorphisms and lactation persistency phenotypes were investigated in 2 breeds (Holsteins and Jerseys). Two genomic regions on chromosome 6 and 1 region on chromosome 26 were found to significantly affect lactation persistency in both breeds. However, the proportion of variance in lactation persistency explained by these markers was small. Our results suggest genomic selection methodology using a large number of markers across the genome to predict breeding values will be a better way to improve this trait than focusing on the significant markers.

Genetic relationships between body condition score and reproduction traits in Canadian Holstein and Ayrshire first-parity cows. By Bastin et al., page 2215. Body condition score is an indicator of the energy balance status of the dairy cow and is therefore linked to production, reproduction, and health. In support of the overall goal to improve fertility and robustness in dairy cattle, the objective of this study was to investigate the genetic relationship between body condition score and female reproduction traits across lactation (including both fertility and calving) for Canadian first-parity dairy cows.

Prediction of unobserved single nucleotide polymorphism genotypes of Jersey cattle using reference panels and population-based imputation algorithms. By Weigel et al., page 2229. Single nucleotide polymorphism genotypes of Jersey cattle were used to evaluate the accuracy of imputation of missing genotypes. Reference panels of 2,542 animals with genotypes for 43,385 single nucleotide polymorphisms were used in conjunction with study samples of 604 animals for which genotypes were available for random subsets of $1,2,5,10,20,40$, or $80 \%$ of loci. Up to $74.3,80.1,90.5,94.2,96.4,98.9$, or $99.5 \%$ of the masked genotypes, respectively, were imputed correctly for animals in the study samples using 2 publicly available algorithms based on hidden Markov models that do not require the genotyping of parents or other close relatives.
Short communication: Genetic and nongenetic factors influencing Ostertagia ostertagi antibodies in UK Holstein-Friesian cattle. By Hayhurst et al., page 2239. The genetic variation and factors affecting antibody level against Ostertagia ostertagi in UK Holstein-Friesian cattle were studied. The antibody response was found to be moderately heritable and the herd and season of sample had significant effects on antibody level.

Short communication: Validation of in vitro fertility genes in a Holstein bull population. By Khatib et al., page 2244. In previous studies, several genes were found to be associated with fertility traits in an in vitro fertilization experimental system. The objective of this study was to validate associations of these genes with fertility traits collected in vivo from a Holstein bull population. Two genes showed significant associations with bull fertility.

Dynamics of culling risk with disposal codes reported by Dairy Herd Improvement dairy herds. By Pinedo et al., page 2250. The objective of this descriptive study was to describe culling risk with different disposal codes in Holstein cows by parity, stage of lactation, milk yield, reproductive status, and herd size in dairy herds enrolled in the Dairy Herd Improvement program. Early lactation was a critical period for culling with disposal codes died, injury/other, and disease. The risk increased with days after calving for disposal codes low production and reproduction. Pregnancy and high milk yield were associated with lower risk of culling with all disposal codes.

Determining the optimum replacement policy for Holstein dairy herds in Iran. By Kalantari et al., page 2262. Dairy culling decisions in Iran are often made in a nonprogrammed way because of a lack of appropriate management tools. A dynamic programming model was designed to optimize replacement decisions under Iranian market conditions, and sensitivity of the system to factors including price of replacement heifers, herd average production, milk price, feed cost, carcass value, and interest rate was evaluated. Herd average production, replacement cost, and risk of involuntary culling were important factors affecting the optimal replacement policy.

Effect of a mixture of steam-flaked corn and soybeans on health, growth, and selected blood metabolism of Holstein calves. By Zhang et al., page 2271. Holstein calves were fed pelleted diets containing extruded, steam-flaked, or ground corn and raw soybeans from 3 to $13 \mathrm{wk}$ of age. Body weight, feed consumption, body structural growth, calf health, and 
selected blood parameters in calves were measured. Better feed efficiency and lower incidence of diarrhea were observed in calves fed the steam-flaked diet than in those fed the extruded or ground diets. Calves on the steam-flaked diet performed better than those fed the other 2 diets.

Capturing urine while maintaining pasture intake, milk production, and animal welfare of dairy cows in early and late lactation. By Clark et al., page 2280. The ability to capture urination events by removing cows from pasture for $16 \mathrm{~h} / \mathrm{d}$ while maintaining milk production, pasture intake, and animal welfare for cows in early and late lactation was determined. An additional 30 to $40 \%$ of urination events were captured while maintaining cow performance and welfare, offering a potential management strategy to reduce nitrogen loss to the environment.

Selection and management of DNA markers for use in genomic evaluation. By Wiggans et al., page 228\%. To facilitate routine genomic evaluation, a database for single nucleotide polymorphism (SNP) genotypes was developed. Historical data were reprocessed to obtain genotypes for 50,972 SNP, and a set of 43,385 SNP was selected for Holsteins, Jerseys, and Brown
Swiss. New edits included parent-progeny conflict and call rates for each SNP; all edits except minor allele frequency were applied across breeds. National genomic evaluations for US dairy cattle have been simplified by using the same set of SNP across breeds, editing SNP genotypes as they are received from laboratories, and providing online access to the database for problem resolution.

Birth traits of pure Holstein calves versus Montbeliarde-sired crossbred calves. By Heins et al., page 2293. Multiparous Holstein cows bred to Montbeliarde artificial insemination (AI) bulls had longer gestation length and greater calf weight at birth than multiparous Holstein cows bred to Holstein AI bulls. Primiparous Jersey $\times$ Holstein crossbred cows bred to Montbeliarde AI bulls had longer gestation length than primiparous pure Holstein cows bred to Holstein AI bulls; however, the resulting crossbred calves did not have greater calf weight at birth. Neither multiparous pure Holstein cows nor Jersey $\times$ Holstein crossbred cows bred to Montbeliarde AI bulls during their first 3 calvings differed significantly for calving difficulty or stillbirth from pure Holstein cows bred to Holstein AI bulls. 